\title{
CURRENT DEVELOPMENTS ON THE COUPLED THERMOMECHANICAL COMPUTATIONAL MODELING OF METAL CASTING PROCESSES
}

\author{
Carlos Agelet de Saracibar ${ }^{1,2 *}$, Michele Chiumenti ${ }^{1,2}$, Miguel $^{*}$ Cervera $^{1,2}$ \\ ${ }^{1}$ International Center for Numerical Methods in Engineering (CIMNE), Barcelona, Spain \\ ${ }^{2}$ ETS Ingenieros de Caminos, Canales y Puertos, Universidad Politécnica de Cataluña, Barcelona, Spain \\ E-mail: agelet@cimne.upc.es, chiumenti@cimne.upc.es, cervera@cimne.upc.es
}

\begin{abstract}
In this paper, current developments on the coupled thermomechanical computational simulation of metal casting processes are presented A thermodynamically consistent constitutive material model is derived from a thermoviscoplastic free energy function. A continuous transition between the initial fluid-like and the final solid-like is modeled by considering a J2 thermoviscoplastic model. Thus, an thermoelastoviscoplastic model, suitable for the solid-like phase, degenerates into a pure thermoviscous model, suitable for the liquid-like phase, according to the evolution of the solid fraction function. A thermomechanical contact model, taking into account the insulated effects of the air-gap due to thermal shrinkage of the part during solidification and cooling, is introduced. A fractional step method, arising from an operator split of the governing differential equations, is considered to solve the coupled problem using a staggered scheme. Within a finite element setting, using low-order interpolation elements, a multiscale stabilization technique is introduced as a convenient framework to overcome the Babuska-Brezzi condition and avoid volumetric locking and pressure instabilities arising in incompressible or quasi-incompressible problems. Computational simulation of industrial castings show the good performance of the model.
\end{abstract}

Key words: coupled, thermomechanical, casting, multiphysics, finite elements

\section{INTRODUCTION. MOTIVATION AND GOALS}

The numerical formulation of coupled thermomechanical solidification processes has been one of the research topics of great interest over the last years. Also, during the last decade, a growing interest on this and related topics has been shown by many industrial companies, such as automotive and aeronautical, motivated by the need to get highquality final products and to reduce manufacturing costs. However, and despite the enormous progress achieved in computational mechanics, the largescale numerical simulation of these problems continues to be nowadays a very complex task. This is mainly due to the highly non-linear nature of the problem, involving non-linear constitutive behavior, liquid-solid phase-change, non-linear thermal and mechanical boundary conditions and thermomechanical contact interaction, among others.

One of the goals of this work is to stress out that a coupled thermo-mechanical model, instead that a purely thermal one, should be used in the numerical simulation of metal die casting processes. Up to now, mostly purely thermal models have been considered to study the evolution of the solidification and cooling phenomena. This is mainly due to the fact that a (purely) thermal analysis is easier and less costly, and therefore more convenient for large scale industrial simulations. In the case of sand die casting 
processes, a purely thermal model could be justified because thermal results are not so much affected by the mechanical behavior due to the low conductivity and stiffness of the sand. However, an accurate modeling of stresses and deformations during the solidification and cooling phases of the part is essential to capture the accurate thermal pattern in metal die casting processes. In fact, the thermal deformation of both part and mold modify the original interfacial heat transfer among all the casting tools involved in the process. The relationship between heat transfer coefficients and air-gap has been closely observed (Hallam et al., 2000). Hence, an accurate prediction of air-gap widths by coupling the thermal simulation with a mechanical simulation is essential to produce a reliable casting model. On the other hand, it must be observed that the mechanical interaction between part and mold induced by the thermal deformations and contact pressure leads to a modification of the final shape and residual stresses of the casting system. An accurate study of the thermal stresses induced during the casting process can prevent mold fissures and an excessive amount

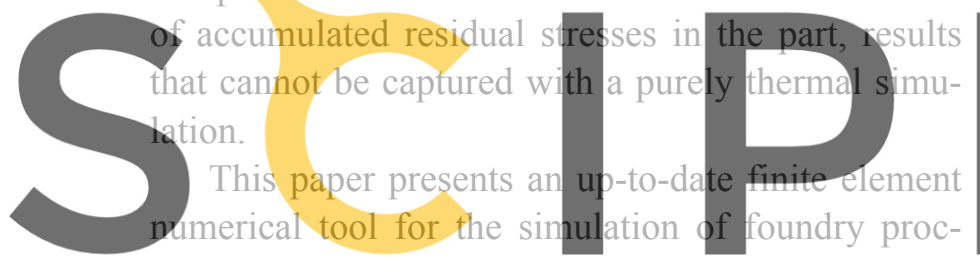

esses. A fully coupled thermo-mechanical formula-

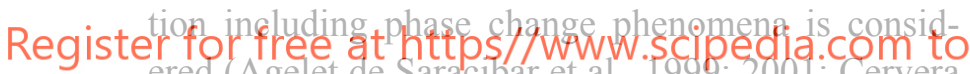
ered (Agelet de Saracibar et al., 1999; 2001; Cervera et al., 1999; Agelet de Saracibar, 2003; Chiumenti, 1999). The mathematical framework to account for both thermal and mechanical constitutive and boundary assumptions is introduced. The proposed constitutive model is consistently derived from a thermo-elasto-viscoplastic free energy function. Mechanical and thermal material properties are assumed to be temperature-dependent. A continuum transition from the initial fluid-like to the finial solid-like behavior of the part is modeled considering a temperature dependent viscoplastic-surface evolution. Phase-change contribution is taken into account assuming both latent-heat release and shrinkage effects. Moreover, an accurate definition of the interfacial heat transfer between the solidifying casting and the mold, essential in producing a reliable casting model, has been considered. In fact, both the solidification process and the temperature evolution strongly depend on the heat exchange at the contact interface. This exchange is affected by the insulating effects of the air-gap due to the ther- mal shrinkage of the casting part during the solidification and cooling phases. A fractional step method, arising from an operator split of the governing differential equations, is considered to solve the coupled problem using a staggered scheme Agelet de Saracibar et al., 1999; 2001; Cervera et al., 1999; Agelet de Saracibar, 2003; Chiumenti, 1999). Within a finite element setting, using low-order interpolation elements, a multiscale stabilization technique is introduced as a convenient framework to overcome the Babuska-Brezzi condition and avoid volumetric locking and pressure instabilities arising in incompressible or quasi-incompressible problems (Agelet de Saracibar et al., 2004; 2006; Cervera et al., 2003; Chiumenti et al., 2002; 2004; Christ et al., 2003; Valverde et al., 2002). Computational simulations of industrial castings using the coupled thermomechanical finite element code VULCAN, developed by the authors at CIMNE and commercialised by QUANTECH (VULCAN), show the good performance of the model.

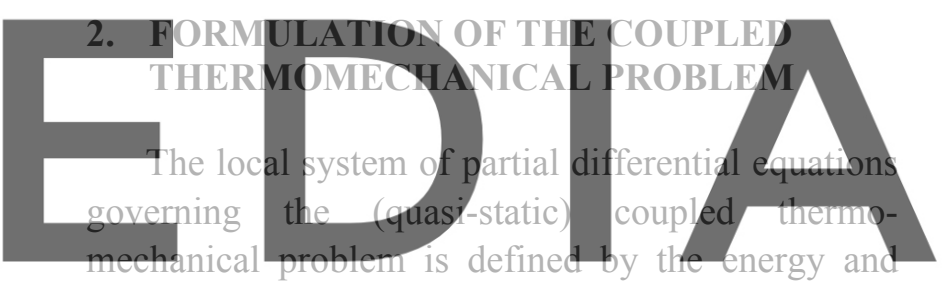

momentum balance equations, restricted by the ine-

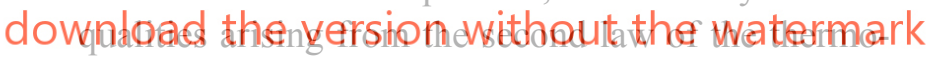
dynamics.

The local form of the energy and momentum balance equations can be written as

$$
\begin{aligned}
\Theta \dot{S} & =-\nabla \cdot \mathbf{q}+R+D_{i n t} \\
\mathbf{0} & =\nabla \cdot \boldsymbol{\sigma}+\mathbf{b}
\end{aligned}
$$

where $\Theta$ is the temperature field, $S$ the specific entropy, $\mathbf{q}$ the heat flux per unit surface, $R$ the prescribed heat sources per unit of volume, $D_{\text {int }}$ the internal dissipation per unit of volume, $\boldsymbol{\sigma}$ is the Cauchy stress tensor and $\mathbf{b}$ the prescribed body forces per unit of volume.

Specific entropy and Cauchy stress tensor are defined by suitable constitutive equations, typically formulated in terms of the internal energy $E$ per unit of volume, and subjected to the restriction on the internal dissipation per unit of volume $D_{i n t}$ arising from the second law of the thermodynamics, given by:

$$
D_{i n t}=\boldsymbol{\sigma}: \dot{\boldsymbol{\varepsilon}}+\Theta \dot{S}-\dot{E} \geq 0
$$


where $\boldsymbol{\varepsilon}$ is the infinitesimal strain tensor and $E$ is the internal energy per unit of volume.

Heat flux $\mathbf{q}$ is defined by a constitutive equation, say Fourier's law, subjected to a restriction on the dissipation by conduction $D_{c o n}$ given by:

$$
D_{\text {con }}=-\frac{1}{\Theta} q \cdot \nabla \Theta \geq 0
$$

Phenomenological models of infinitesimal strain plasticity adopt a local additive decomposition of the infinitesimal strain tensor into elastic and plastic parts. Hardening mechanisms in the material are characterized by an additional set of phenomenological internal variables in the strain space, collectively denoted here as $\xi_{\alpha}$. An additive split of the local entropy into elastic and plastic parts is also adopted, where the plastic entropy is viewed as an additional internal variable arising as a result of dislocation and lattice defect motion. The above considerations motivate the following additive split of the infinitesimal strain, local entropy and set of internal variables:

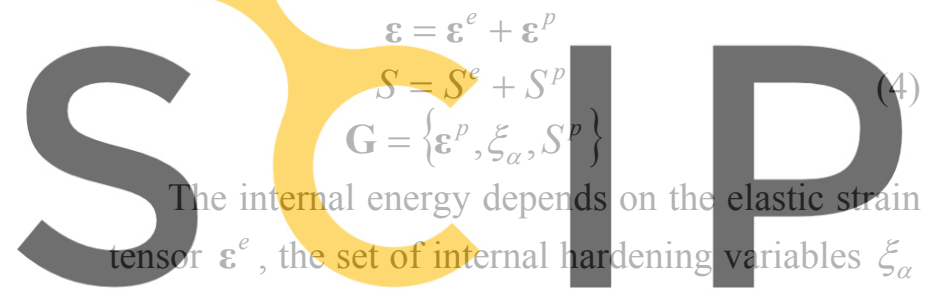

and the local elastic entropy $S^{e}$ taking the functional

Regis甲ep: for free at https//www.scipedia.com $E=\hat{E}\left(\varepsilon^{e}, \xi_{\alpha}, S^{e}\right)$

Introducing the functional form of the internal energy into the expression of the internal dissipation (2), taking the time derivative, applying the chain rule and using the additive split of the infinitesimal strain tensor and local entropy, a straightforward argument yields the following constitutive equations and reduced internal dissipation:

$$
\begin{gathered}
\boldsymbol{\sigma}=\partial_{\varepsilon^{e}} \hat{E}\left(\boldsymbol{\varepsilon}^{e}, \xi_{\alpha}, S^{e}\right) \\
\Theta=\partial_{S^{e}} \hat{E}\left(\boldsymbol{\varepsilon}^{e}, \xi_{\alpha}, S^{e}\right) \\
\beta^{\alpha}=\partial_{\xi_{\alpha}} \hat{E}\left(\boldsymbol{\varepsilon}^{e}, \xi_{\alpha}, S^{e}\right) \\
D_{\text {int }}=D_{\text {mech }}+D_{\text {ther }} \geq 0 \text { with } \\
D_{\text {mech }}=\boldsymbol{\sigma}: \dot{\boldsymbol{\varepsilon}}^{p}+\beta^{\alpha} \cdot \dot{\boldsymbol{\xi}}_{\alpha} \geq 0, D_{\text {ther }}=\Theta \dot{H}^{p}
\end{gathered}
$$

Using the Legendre transformation $\Psi=E-\Theta H^{e}$, the free energy function takes the functional form:

$$
\Psi=\hat{\Psi}\left(\varepsilon^{e}, \xi_{\alpha}, \Theta\right)
$$

Taking the time derivative of the free energy function (7) and applying the chain rule, a straightforward yields the following alternative expressions for the constitutive equations:

$$
\begin{gathered}
\boldsymbol{\sigma}=\partial_{\varepsilon^{e}} \hat{\Psi}\left(\boldsymbol{\varepsilon}^{e}, \xi_{\alpha}, \Theta\right) \\
S^{e}=\partial_{S^{e}} \hat{\Psi}\left(\boldsymbol{\varepsilon}^{e}, \xi_{\alpha}, \Theta\right) \\
\beta^{\alpha}=\partial_{\xi_{\alpha}} \hat{\Psi}\left(\boldsymbol{\varepsilon}^{e}, \xi_{\alpha}, \Theta\right) \\
D_{\text {int }}=D_{\text {mech }}+D_{\text {ther }} \geq 0 \text { with } \\
D_{\text {mech }}=\boldsymbol{\sigma}: \dot{\boldsymbol{\varepsilon}}^{p}+\beta^{\alpha} \cdot \dot{\xi}_{\alpha} \geq 0, D_{\text {ther }}=\Theta \dot{H}^{p}
\end{gathered}
$$

1. Formulation of the Thermal Problem Using the additive split of the local entropy into elastic and plastic parts given in (4) and the additive split of the internal dissipation into mechanical and thermal part given in (6), the energy balance equation can be written as:

$$
\Theta \dot{S}^{e}=-\nabla \cdot \mathbf{q}+R+D_{\text {mech }}
$$

Alternatively, using the constitutive equation for the elastic entropy given in (8), taking its time derivative and applying the chain rule, the energy bal-

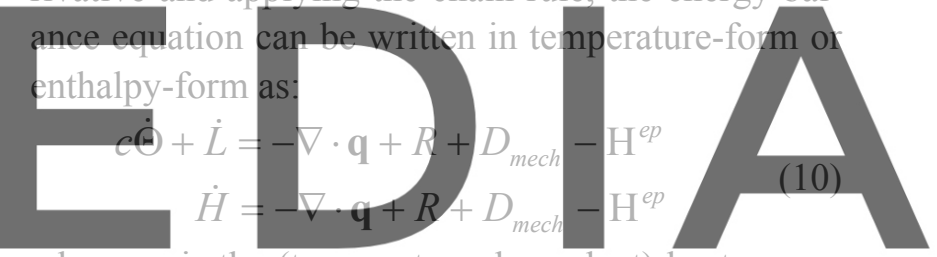

where $c$ is the (temperature dependent) heat capac-

\section{ity $L$ is the latent heat. $H^{e p}$ is.the elastoplastic heat-} download the version without the watermark tion and elastoplastic heating can be considered as negligible for casting processes, in comparison with the heat flux generated by the thermal gradient between the part and mold.

The rate of latent heat released during the solidification process can be computed in terms of the solid fraction function $f_{S}(\Theta)$ as:

$$
\dot{L}=-L^{p c} \frac{d f_{S}(\Theta)}{d \Theta} \dot{\Theta}
$$

where $L^{p c}$ is the total amount of heat realeased during the phase-change and the solid fraction function satisfies

$$
\begin{array}{lll}
f_{S}(\Theta)=0 & \text { if } & \Theta \geq \Theta_{L} \\
f_{S}(\Theta)=1 & \text { if } & \Theta \leq \Theta_{S}
\end{array}
$$

where $\Theta_{L}$ is the liquidus temperature and $\Theta_{S}$ is the solidus temperature, and a non linear interpolation function is used to compute the solid fraction in the mushy zone. 
The heat flux $\mathbf{q}$ is computed as a function of the temperature field using Fourier's law as:

$$
\mathbf{q}=-k(\Theta) \nabla \Theta
$$

where $k(\Theta)$ is the temperature-dependent heat conductivity.

Let $\Omega$ be the integration domain with smooth boundaries $\partial \Omega$. Let $\delta \vartheta$ be the test function associated to the temperature field $\Theta$. Denoting by $\langle\cdot$,$\rangle the$ inner product in $L^{2}(\Omega)$, the weak form of the energy balance equation (neglecting the mechanical disspation and elastoplastic heating terms) takes the following expression Agelet de Saracibar et al., 1999; 2001; Cervera et al., 1999; Agelet de Saracibar, 2003; Chiumenti, 1999):

$$
\begin{gathered}
\langle C \dot{\Theta}+\dot{L}, \delta \vartheta\rangle+\langle k \nabla \Theta, \nabla \vartheta\rangle= \\
\langle R, \delta \vartheta\rangle-\langle\bar{q}, \delta \vartheta\rangle_{\partial \Omega}-\left\langle q_{\text {cond }}+q_{\text {conv }}+q_{\text {rad }}, \delta \vartheta\right\rangle_{\partial \Omega}
\end{gathered}
$$

where $\bar{q}$ is the prescribed normal heat flux on the boundary and $q_{\text {cond }}, q_{\text {conv }}, q_{\text {rad }}$ are the conduction, convection and radiation heat fluxes, respectively, at the contact interfaces of the casting tools.

The last term of the weak form defined above is obably the most import solidification and cooling

observe either experimentally (Hallam et al., 2000)
or numerically Agelet de Saracibar, 1999; 2001;
Cervera et al. 1999; A delet de Saracibar, 2003;

Chiumenti, 1999) that a reliable solidification model

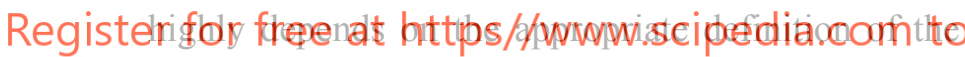
thermo-mechanical heat transfer at the contact interface.

Assuming that only small deformations of the casting tools can occur, the radiation heat flux $q_{\mathrm{rad}}$ can be computed as a direct function of the surface temperatures $\Theta_{c}$ and $\Theta_{m}$ of the two bodies in contact and their emissivities $\varepsilon_{c}$ and $\varepsilon_{m}$ as:

$$
q_{\text {rad }}=\frac{\sigma_{a}\left(\Theta_{c}^{4}-\Theta_{m}^{4}\right)}{\left(1 / \varepsilon_{c}+1 / \varepsilon_{m}-1\right)}
$$

On the other hand, heat conduction through the contact surface, $q_{\text {cond }}$, can be assumed to be proportional to the thermal gap $g_{\Theta}$ between the contact surfaces, in the form:

$$
q_{\text {cond }}=h_{\text {cond }} g_{\Theta}
$$

In this case the surfaces of the two bodies are in contact that is no macroscopical air-gap is formed due to the thermal shrinkage of the casting during the cooling phase. As a consequence, the model assumes that a thermal resistance, $R_{\text {cond }}$, only arises as a result of the air (gasses) trapped between the mold and the casting surfaces, due to the roughness values measured on those surfaces. In addition, the thermal resistance due to the mold coating can be also considered. As a result, the total thermal resistance $R_{\text {cond }}$, can be computed as (Hallam et al., 2000):

$$
R_{\text {cond }}=0.5 \frac{R_{z}}{k_{a}}+\frac{\delta_{c}}{k_{c}}
$$

where $R_{z}=\sqrt{R_{z, \text { cast }}^{2}+R_{z, \text { mold }}^{2}}$ is the mean peak-tovalley height of the rough surfaces, $\delta_{c}$ is the effective thickness of the coating and $k_{a}$ and $k_{c}$ are the thermal conductivity of the gas trapped and the coating, respectively. Moreover, it is also possible to assume that the microscopical interaction between the contact surfaces depends on the normal contact pressure $t_{N}$ so that the heat conduction coefficient $h_{\text {cond }}$ can be defined using the following expression:

$$
h_{\text {cond }}\left(t_{N}\right)=\frac{1}{R_{\text {cond }}}\left(\frac{t_{N}}{H_{e}}\right)
$$

where $H_{e}$ is the Vickers hardness and $0.6 \leq n \leq 1.0$

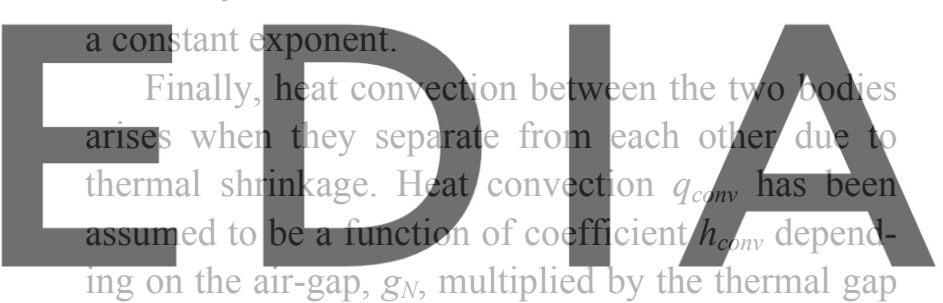

ing on the air-gap, $g_{N}$, multiplied by the thermal gap dowiflo in the form (Ransing and Lewis 1998 ) $q_{\text {conv }}=h_{\text {conv }}\left(g_{N}\right) g_{\Theta}$

In this case, the heat transfer coefficient $h_{c o n v}$ is defined by the inverse of the thermal resistances of both air-gap and coating as:

$$
h_{\text {conv }}=\frac{1}{\max \left(g_{N}, R_{z}\right) / k_{a}+\delta_{c} / k_{c}}
$$

Observe that both heat conduction and heat convection coefficients depend on mechanical quantities such as the contact pressure or the air-gap induced by the actual deformation of the casting tools. As a consequence, the solidification and cooling processes are driven by a heat exchange at the contact interfaces that is non-uniform and that in general cannot be expressed as a direct function of the temperature field. This is the main reason why a fully coupled thermo-mechanical simulation is required.

\section{Formulation of the mechanical problem The} mechanical model for the cast part and the mold material has been formulated to take into account many important features as thermal shrinkage of the 
cast during the phase-change, a smooth transition from the liquid-like to a solid-like behavior and the incompressibility constraint when the casting is still liquid, among others. To deal with these complex phenomena the mechanical model chosen is based on the recent developments of the authors in the fields of incompressibility in solid mechanics (Agelet de Saracibar et al., 2004; 2006; Cervera et al., 2003; Chiumenti et al., 2002; 2004; Christ et al., 2003; Valverde et al., 2002). The mixed variational formulation proposed uses linear displacements and pressure interpolations, leading to robust and flexible triangular or tetrahedral elements suitable for large-scale computation of constrained media problems. An orthogonal sub-grid scale approach, introduced by Codina in the field of CFD (Codina, 2000; 2002), is assumed as an attractive alternative to circumvent the Babuska-Brezzi stability condition (Brezzi and Fortin, 1991).

The strong format of the momentum balance equation is stated introducing the hydrostatic pressure $p$, as an independent unknown, additional to the displacement field, $\mathbf{u}$, as:

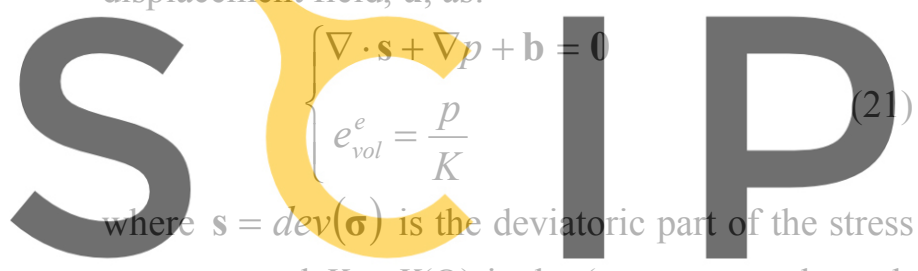

tensor $\sigma$ and $K=K(\Theta)$ is the (temperature depend-

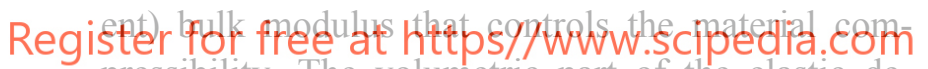
pressibility. The volumetric part of the elastic de-

formation $e_{v o l}^{e}$ is defined as:

$$
e_{v o l}^{e}=\operatorname{tr}\left(\boldsymbol{\varepsilon}^{e}\right)=\nabla \cdot \mathbf{u}-e^{\vartheta}(\Theta)
$$

where the thermal deformation $e^{\vartheta}(\Theta)$ is computed taking into account the shrinkage effects during liquid to solid phase-change and the thermal deformation during cooling as follows:

$$
e^{\vartheta}(\Theta)=\left\{\begin{array}{lll}
0 & \text { if } & \Theta>\Theta_{L} \\
e^{p c}(\Theta) & \text { if } & \Theta_{S} \leq \Theta \leq \Theta_{L} \\
e^{c o o l}(\Theta) & \text { if } & \Theta \leq \Theta_{S}
\end{array}\right.
$$

where $e^{p c}(\Theta)$ and $e^{\text {cool }}(\Theta)$ are the thermal shrinkage during phase-change and the thermal deformation during cooling phase, respectively defined as:

$$
\begin{aligned}
& e^{p c}(\Theta)=\frac{\Delta V^{p c}}{V_{0}} f_{S}(\Theta)=\frac{\rho(\Theta)-\rho_{L}}{\rho_{S}} \\
& e^{c o o l}(\Theta)=3 \alpha(\Theta)\left(\Theta-\Theta_{r e f}\right)-3 \alpha\left(\Theta_{S}\right)\left(\Theta_{S}-\Theta_{r e f}\right)
\end{aligned}
$$

being $\alpha(\Theta)$ the (temperature dependent) dilatation coefficient, $V_{0}$ the reference volume at the initial casting temperature and $\Delta V^{p c}$ the total volume change experimentally observed during the phase change.

As a result of the stabilized formulation proposed by the authors in (Agelet de Saracibar et al., 2004; 2006; Cervera et al., 2003; Chiumenti et al., 2002; 2004; Christ et al., 2003; Valverde et al., 2002), the weak form of the balance of momentum equation accounting for the incompressibility behavior is the following:

$$
\left\{\begin{array}{l}
\left\langle\nabla^{s} \mathbf{v}, \mathbf{s}\right\rangle+\langle\nabla \cdot \mathbf{v}, p\rangle=\langle\mathbf{v}, \mathbf{b}\rangle+\langle\mathbf{v}, \overline{\mathbf{t}}\rangle \\
\left\langle q, e_{v o l}^{e}\right\rangle-\left\langle q, \frac{p}{K}\right\rangle-\sum_{e=1}^{\text {Nelem }} \tau_{e}\langle\nabla q, \nabla p-\mathbf{\Pi}\rangle=0
\end{array}\right.
$$

where $\boldsymbol{\Pi}$ is the smooth projection of the pressure gradient onto the finite element space, computed at each time-step as:

$$
\langle\eta, \Pi\rangle-\langle\eta, \nabla p\rangle=0
$$

Observe that in case of liquid-like behavior, $K \rightarrow \infty$ and $e^{\vartheta}=0$, so that the second equation in (25) transforms into:

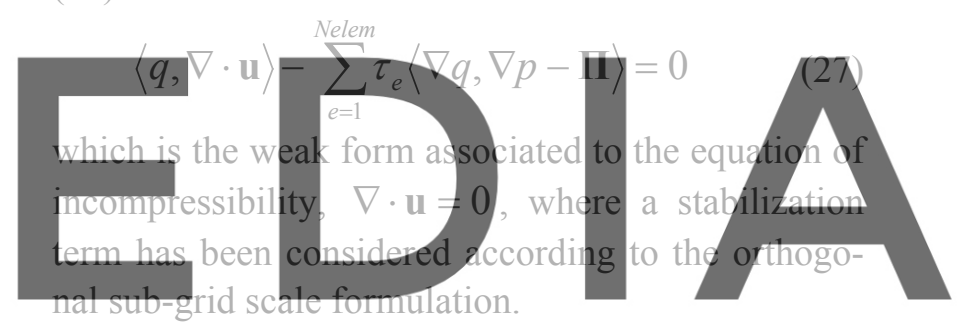

The mechanical model for the cast part and the

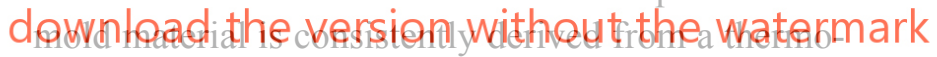
elasto-viscoplastic free-energy potential. Constitutive equations for the deviatoric part of the stress tensor $\mathbf{s}$ together with the kinematic and isotropic hardening stress-like variables $\mathbf{q}$ and $q$, respectively, are described by the following equations:

$$
\begin{aligned}
& \mathbf{s}=2 G \operatorname{dev}\left(\boldsymbol{\varepsilon}-\boldsymbol{\varepsilon}^{v p}\right) \\
& \mathbf{q}=-f_{S}(\Theta) \frac{2}{3} K_{\xi} \xi \\
& q=-f_{S}(\Theta)\left[\left(\sigma_{\infty}-\sigma_{0}\right)(1-\exp (\delta \xi))+H \xi\right]
\end{aligned}
$$

where $G=G(\Theta)$ is the (temperature dependent) shear modulus, $K_{\xi}$ and $H$ are the coefficients of the linear kinematic and isotropic hardening laws and finally, $\sigma_{\infty}=\sigma_{\infty}(\Theta)$ and $\sigma_{0}=\sigma_{0}(\Theta)$ are the (temperature dependent) saturation and initial flow stress parameters.

The viscoplastic strains $\boldsymbol{\varepsilon}^{v p}$ are derived, together with the evolution laws for the kinematic and isotropic strain hardening variable $\xi$ and $\xi$, according to the principle of maximum plastic dissipation as: 


$$
\begin{aligned}
& \dot{\boldsymbol{\varepsilon}}^{v p}=\gamma \frac{\partial \Phi(\mathbf{s}, \mathbf{q}, q, \Theta)}{\partial \mathbf{s}}=\gamma \mathbf{n} \\
& \dot{\boldsymbol{\xi}}=\gamma \frac{\partial \Phi(\mathbf{s}, \mathbf{q}, q, \Theta)}{\partial \mathbf{q}}=-\gamma \mathbf{n} \quad \text { where }:\left\{\begin{array}{l}
\mathbf{n}=\frac{\mathbf{s}-\mathbf{q}}{\|\mathbf{s}-\mathbf{q}\|} \\
\gamma=\frac{1}{\eta}\langle\Phi(\mathbf{s}, \mathbf{q}, q, \Theta)\rangle^{n}
\end{array}\right. \\
& \dot{\xi}=\gamma \frac{\partial \Phi(\mathbf{s}, \mathbf{q}, q, \Theta)}{\partial q}=\gamma \sqrt{\frac{2}{3}}
\end{aligned}
$$

where $\mathbf{n}$ and $\gamma$ are the unit normal to the yield surface and the viscoplastic multiplier, respectively. It is possible to observe that the model considers a temperature dependent $\mathrm{J} 2$ yield surface and plastic potential $\Phi(\mathbf{s}, \mathbf{q}, q, \Theta)$ defined as:

$$
\Phi(\mathbf{s}, \mathbf{q}, q, \Theta)=\|\mathbf{s}-\mathbf{q}\|-R(q, \Theta)
$$

where $R(q, \Theta)$ is the (temperature dependent) yieldsurface radio defined as:

$$
R(q, \Theta)=f_{S}(\Theta) \sqrt{\frac{2}{3}}\left[\sigma_{0}(\Theta)-q\right]
$$

It must be pointed out that the yield-surface radio, as well as the hardening effects, gradually reduce as the temperature increase, vanishing when liquidus temperature is reached. As a result, a purely viscous Norton model is behavior must be simulated. toric stress tensor is simply
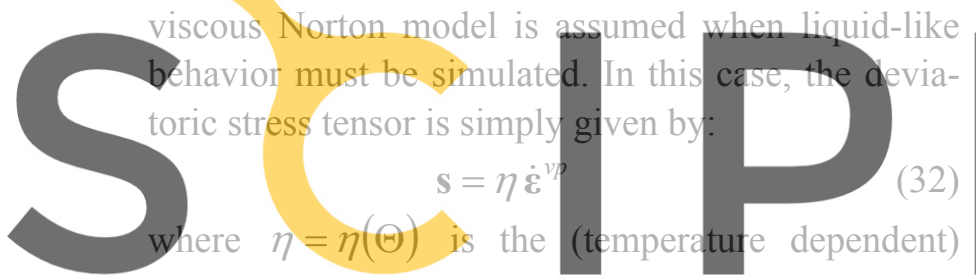

viscosity parameter.
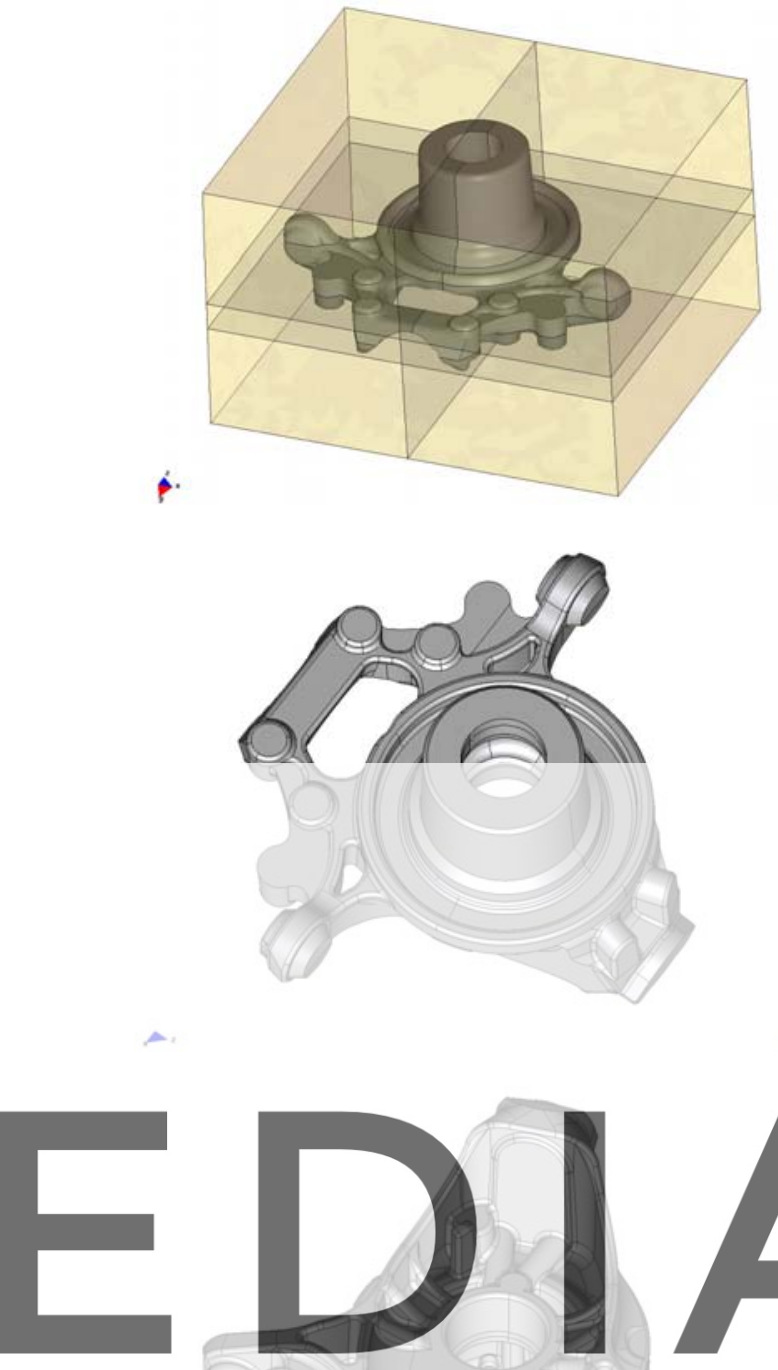

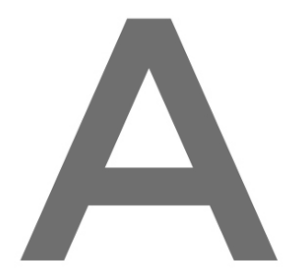

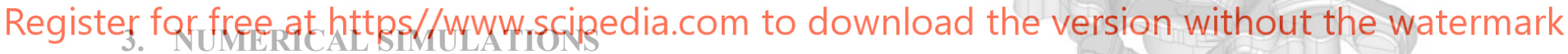

The formulation presented in previous sections is illustrated here with a number of numerical simulations. The goal is to demonstrate the good performance of the proposed formulation in the framework of infinitesimal strain coupled thermalplasticity for an industrial casting analysis, in particular for steel mold castings. Computations are performed with the finite element code VULCAN developed by the authors at the International Center for Numerical Method in Engineering (CIMNE) in Barcelona, Spain, and commercialized by QUANTECH ATZ (VULCAN).

In all the simulations the Newton-Raphson method, combined with a line-search optimization procedure, is used to solve the nonlinear system of equations arising from the spatial and temporal discretization of the weak form of the governing equations. Convergence of the incremental iterative solution procedure was monitored by requiring a tolerance of $0.1 \%$ in the residual based error norm.

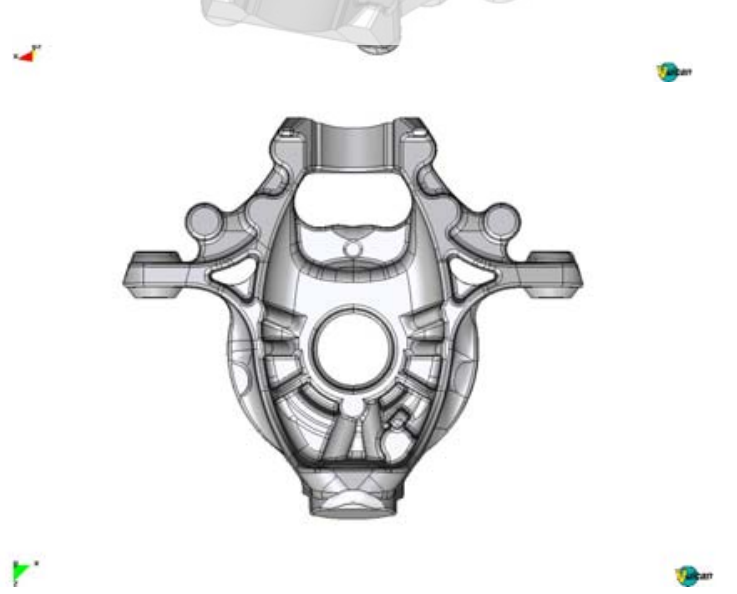

Fig. 1. Different views of the geometry of the part

1. First numerical simulation The first example is concerned with the solidification process of an iron casting specimen in a sand mould. Figures 1 and 2 show different views of the geometry and finite element mesh used for the part. The full mesh, including the mold, consists of 237,126 tetrahedral elements. Figure 3 shows the distribution of solid frac- 
tion at time $500 \mathrm{~s}$. and Figure 4 shows the temperature distribution at $1100 \mathrm{~s}$. Figures 5 and 6 show J2 von Mises deviatoric stress and displacement module distributions, respectively, at different sections
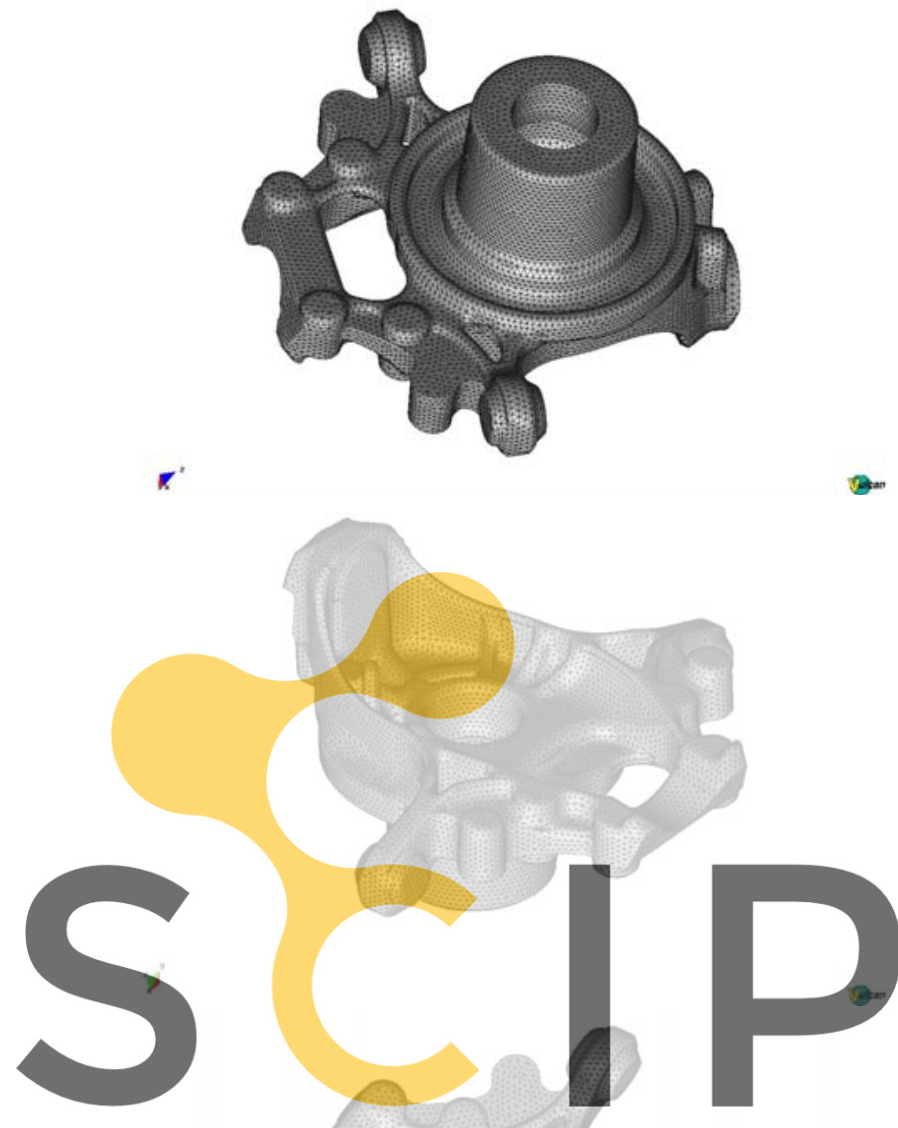

Register for free at https//www.scipedia.com

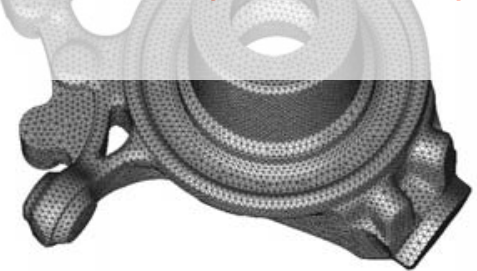

Fig. 2. Different views of the finite element mesh of the part

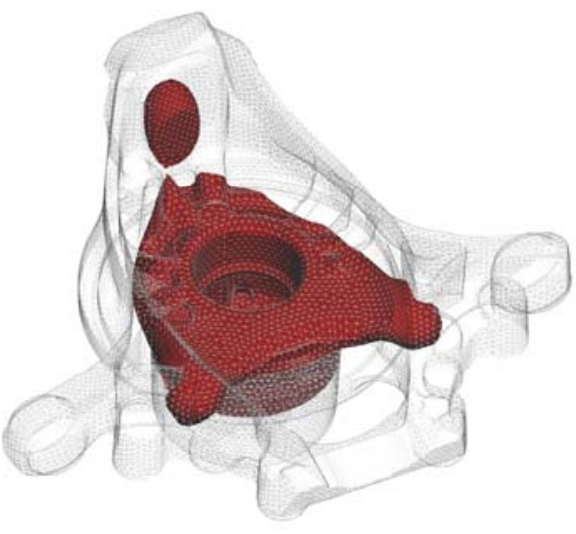

Fig. 3. Solid fraction contour at time $500 \mathrm{~s}$.

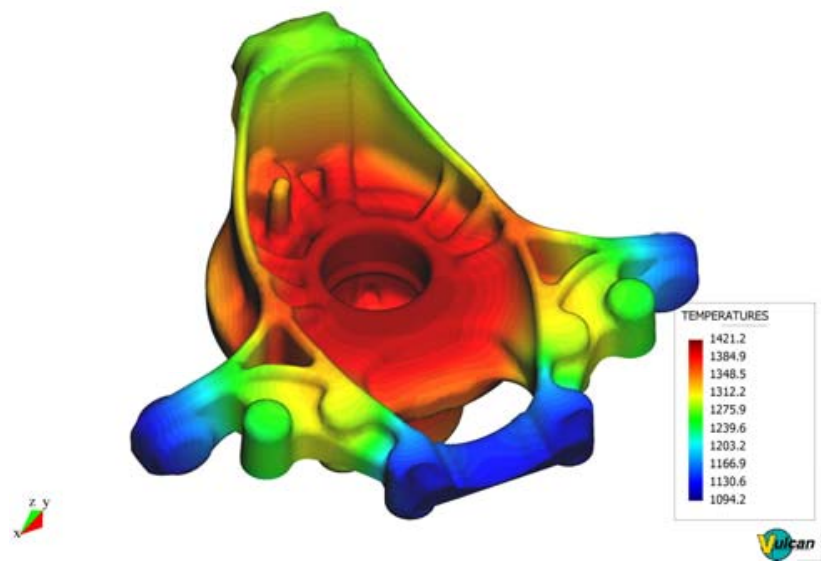

Fig. 4. Temperatures distribution at time 1100 s.

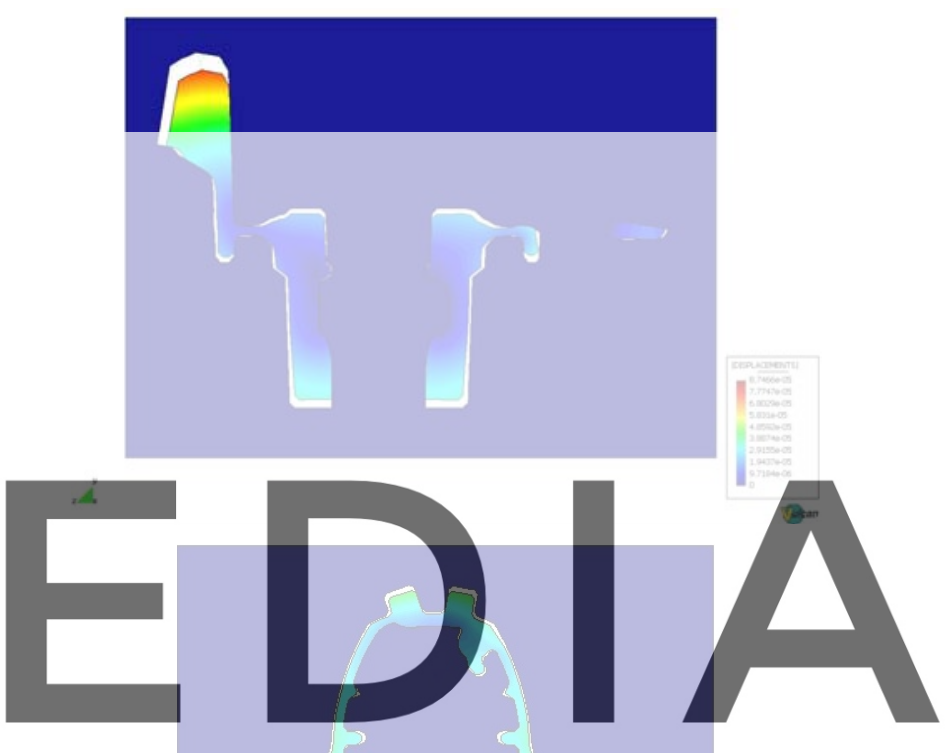



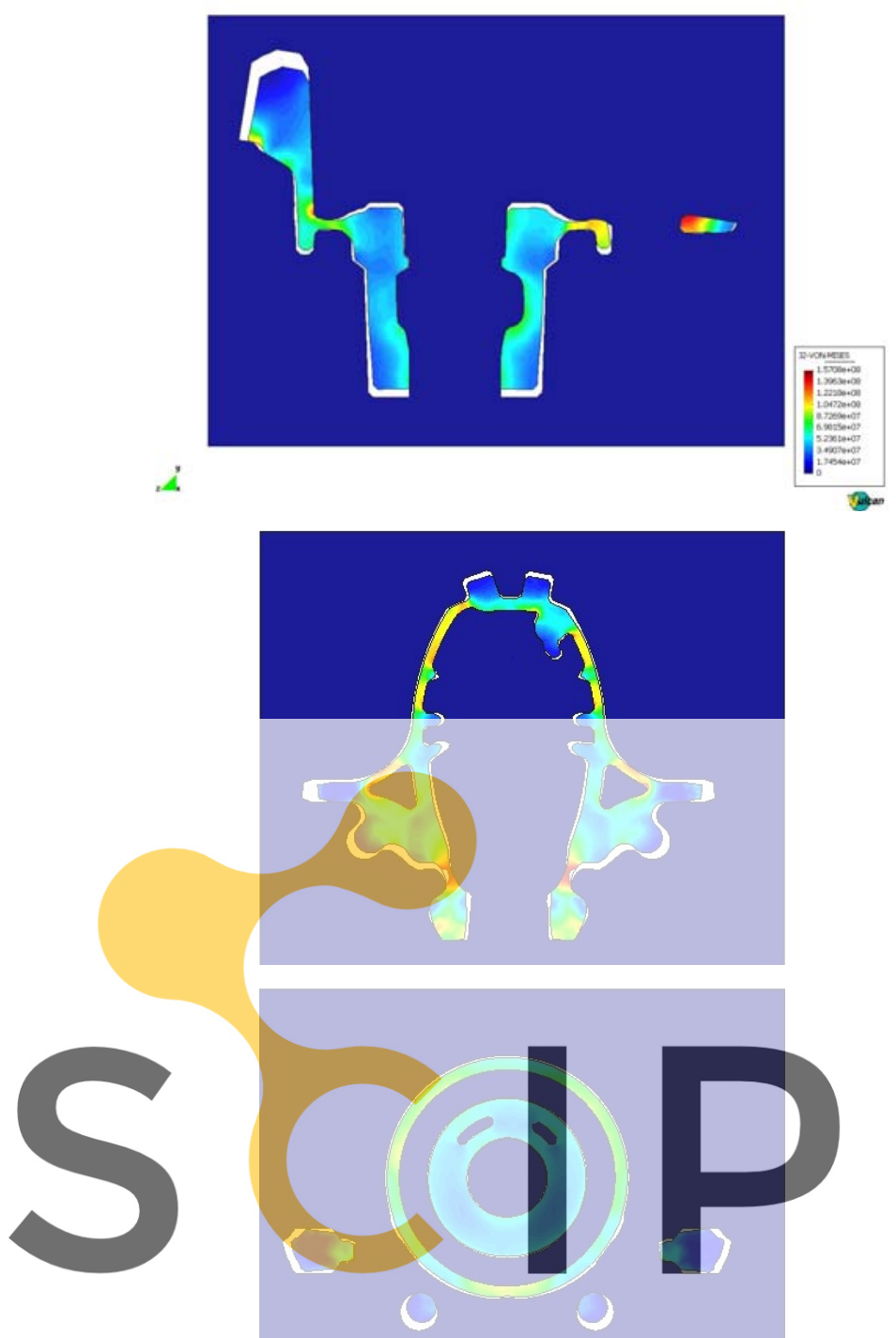

Register for free at https//www.scipedia.com to

Fig. 6. Contours of displacement modules at different sections of the part

2. Second numerical simulation The second example is concerned with the solidification process of an aluminium (AlSi7Mg) specimen in a steel (X40CrMoV5) mold. Geometrical and material data were provided by RUFFINI. Figure 7 shows a view of the finite element mesh used for the part and the cooling system. The full mesh, including the mold, consists of 380.000 tetrahedral elements. Aluminium material behavior has been modeled by the fully coupled thermo-viscoplastic model, while the steel mold behavior has been modeled by a simpler thermo-elastic model. The initial temperature is $650^{\circ} \mathrm{C}$ for the casting $250^{\circ} \mathrm{C}$ for the mold. Cooling system has been kept at $20^{\circ} \mathrm{C}$. The heat transfer coefficient takes into account the air-gap resistance due to the casting shrinkage. Temperature and solid fraction distribution during solidification is shown in

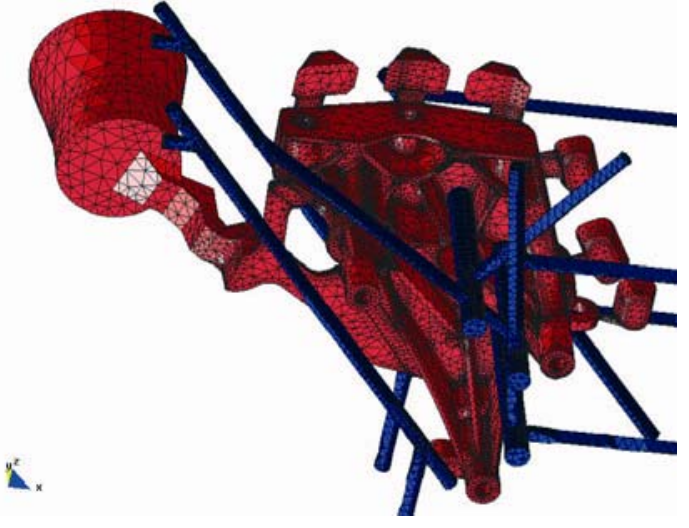

Fig. 7. Geometry and finite element discretization of the RUFFINI aluminium casting and cooling system

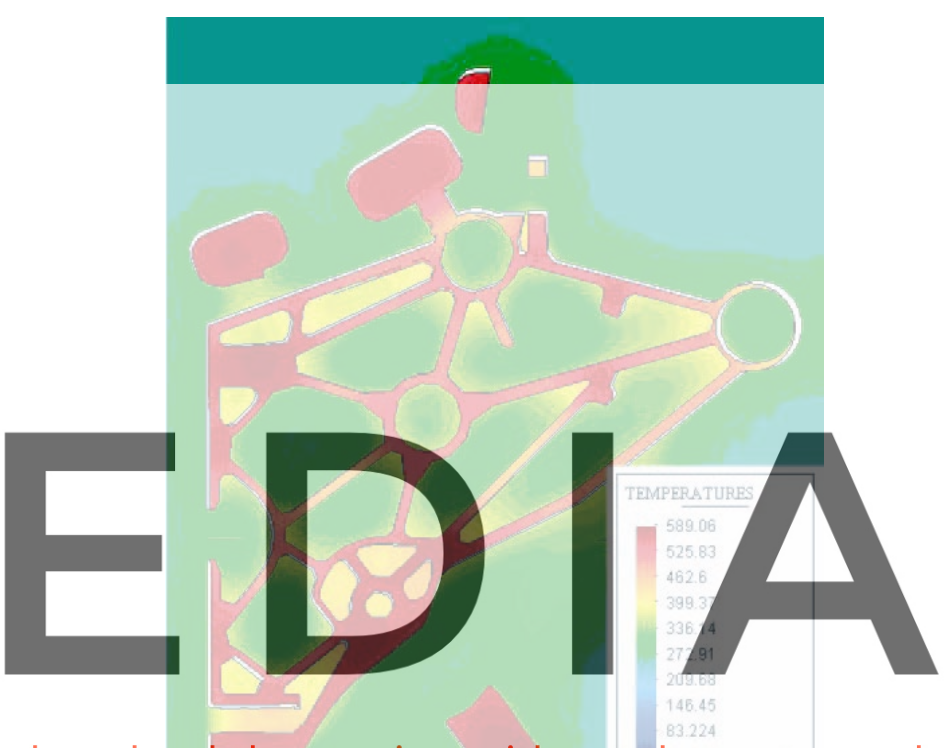

download the version without the watermark

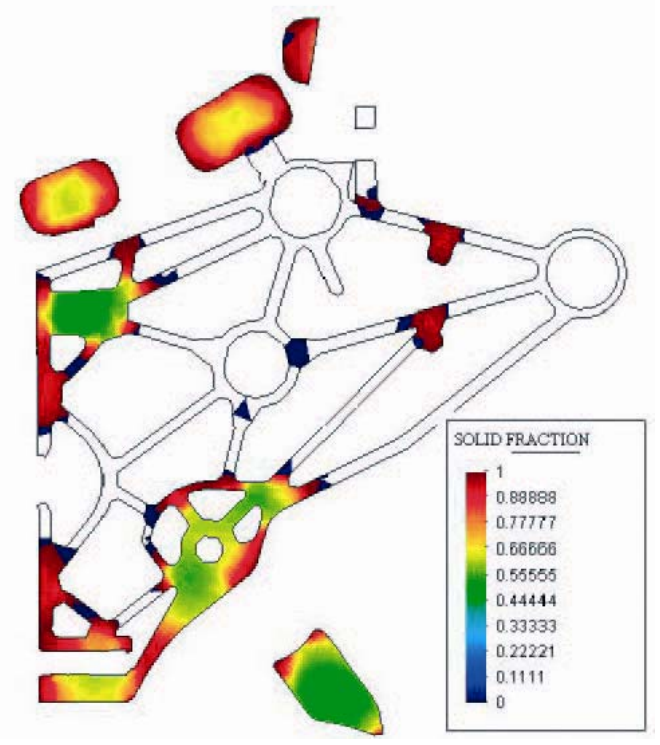

Fig. 8. Temperature and solid fraction distribution during phase change (plane $x y$ ) 


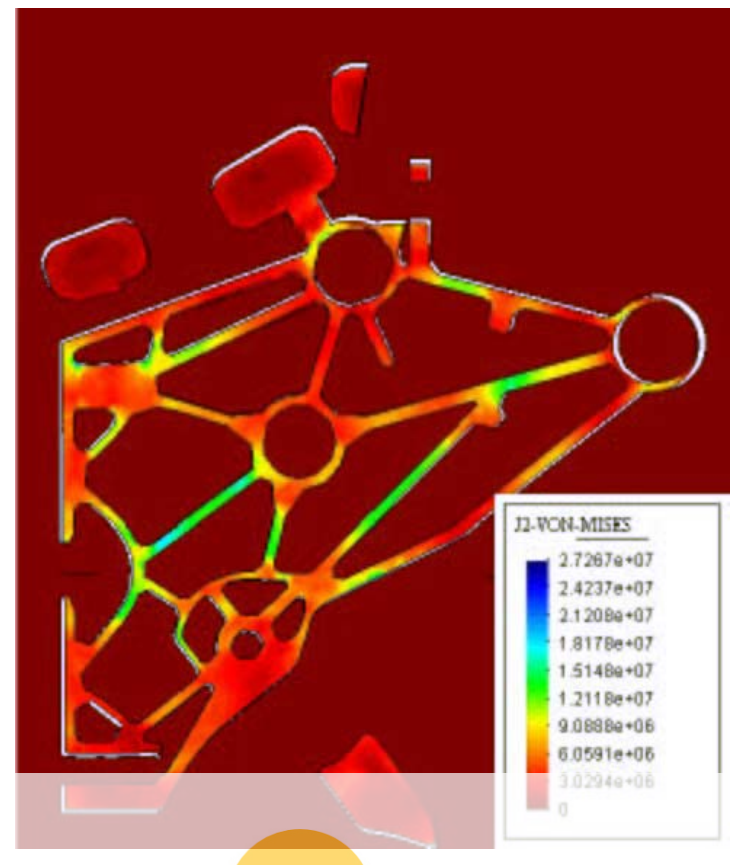

consists of 580.000 tetrahedral P1P1 elements. Aluminium material behaviour has been modeled by the fully coupled thermoviscoplastic model, while the steel mold behaviour has been modeled by a simpler thermoelastic model. The initial temperature is $650^{\circ} \mathrm{C}$ for the casting and $250^{\circ} \mathrm{C}$ for the mold. Cooling system has been kept at $20^{\circ} \mathrm{C}$. The heat transfer coefficient takes into account the air-gap resistance due to the casting shrinkage. Temperature evolution as well as thermal shrinkage during solidification are shown in Figure 11. Figure 12 shows the temperature, von Mises deviatoric stress and equivalent plastic strain distributions.

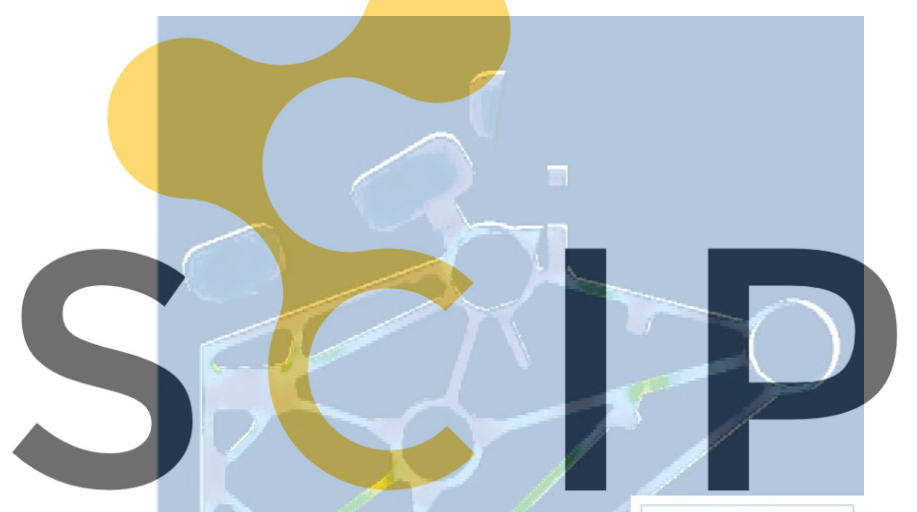

Register for free at https//www.scipedia.com to download the version without the watermark

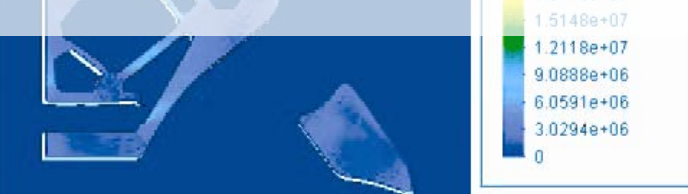

Fig. 9. Mean pressure and von Mises deviatoric effective stress during phase change (plane $x y$ )

Figure 8. Figure 9 shows the mean pressure and von Mises deviatoric effective stress distributions in a $\mathrm{x}$ $\mathrm{y}$ section. In these figures it is also possible to appreciate the air-gap between the part and the mold, responsible of a non-uniform heat flux at the contact interface.

3. Third numerical simulation The third example is concerned with the solidification process of an aluminium (AlSi7Mg) motor block in a steel (X40CrMoV5) mold. Geometrical and material data were provided by TEKSID. Figure 10 shows a view of the finite element mesh used for the part and the cooling system. The full mesh, including the mold,
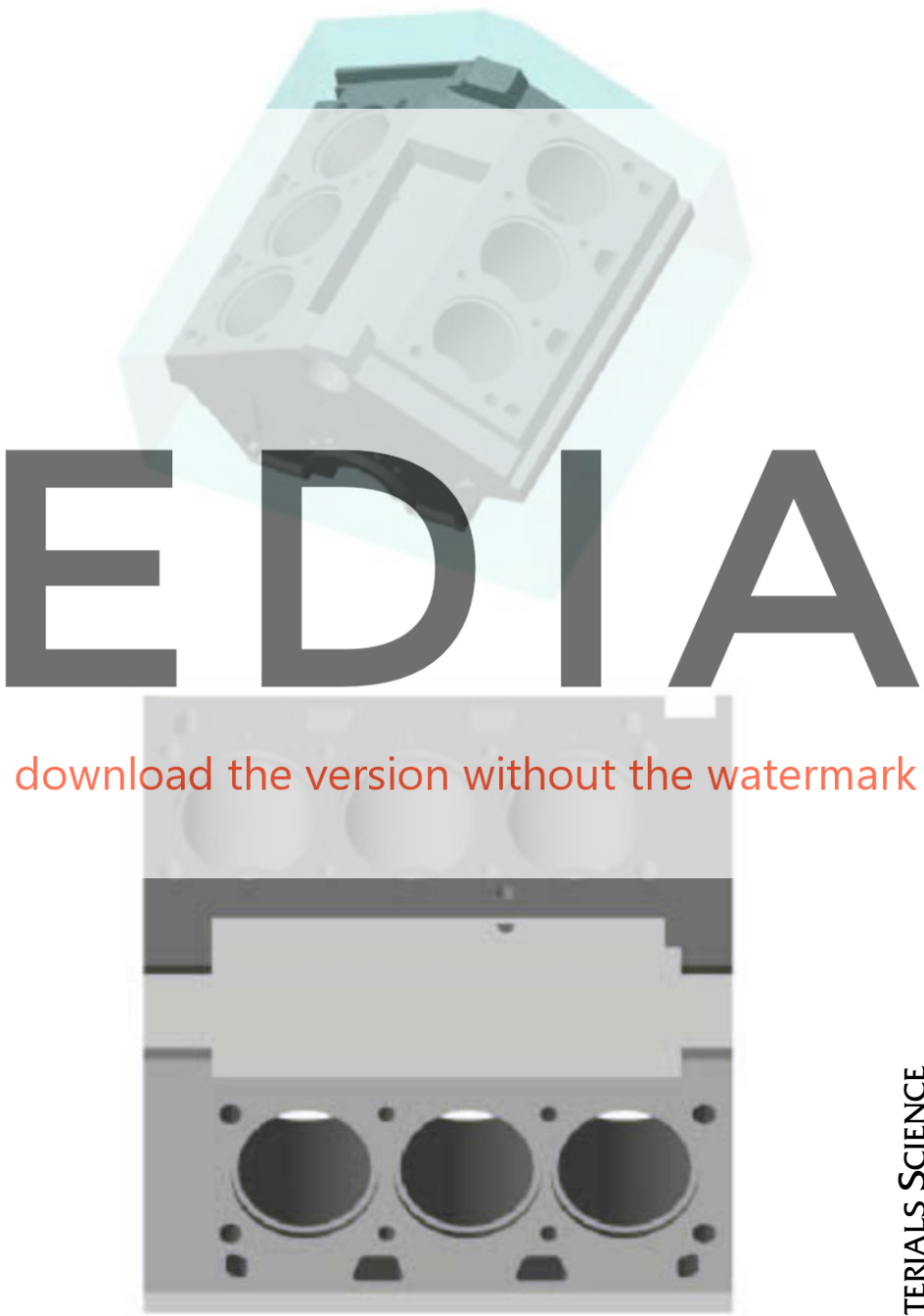

Fig. 10. Geometry of a TEKSID aluminium motor-block casting and mould system

\section{CONCLUDING REMARKS}

A formulation for coupled thermo-mechanical problems has been presented. An enthalpy format of the balance of energy equation has been considered to control the latent-heat released during phasechanges. Stress analysis is essential to define both 
conduction and convection heat transfer at the contact interfaces. A particular J2 thermoplastic model has been considered. Temperature dependency of both mechanical properties and yield surface allows to predict deformations and final residual stresses of the casting tools involved. The model has been successfully applied to the numerical simulation of industrial foundry processes.

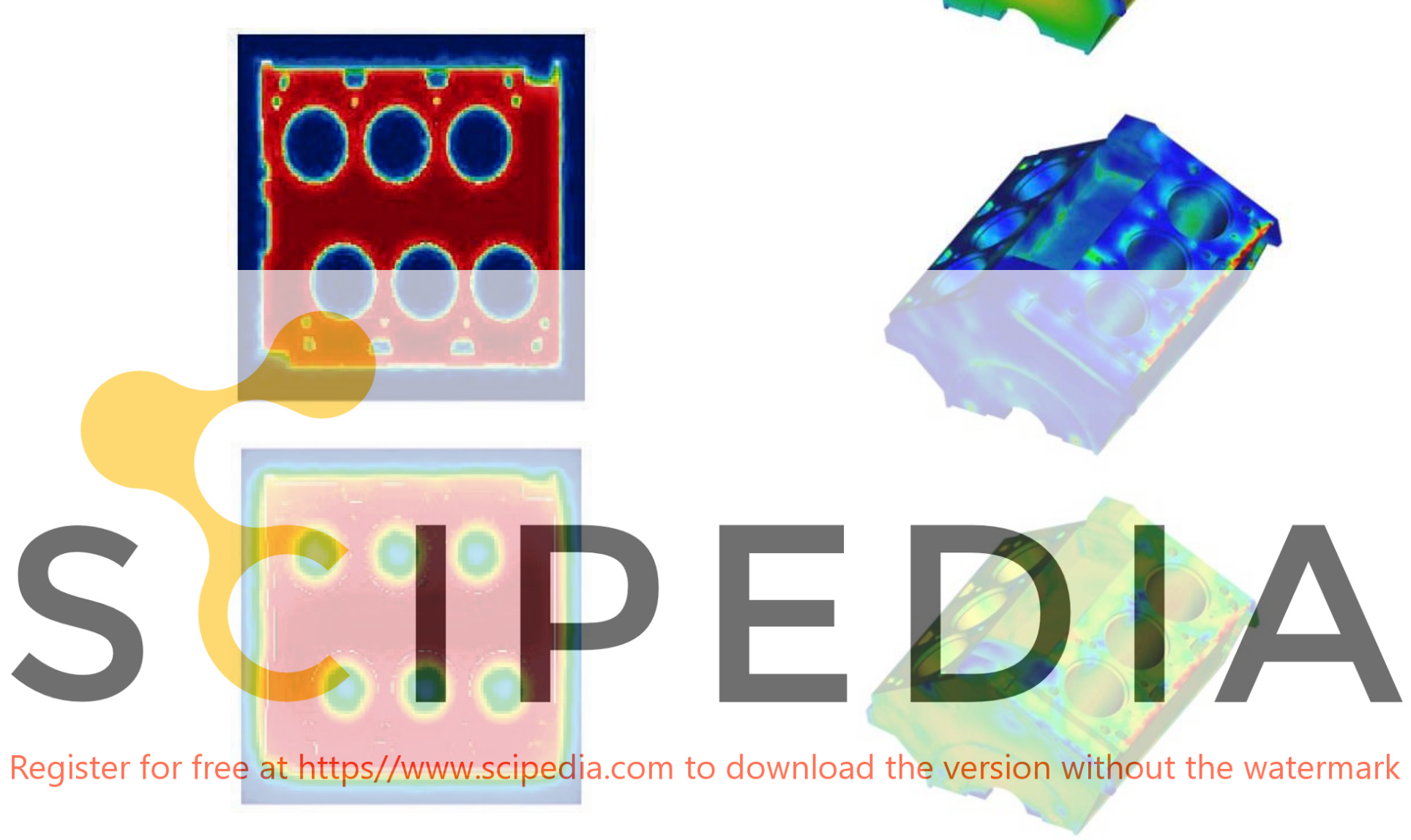

Fig. 12. Temperature (a), J2 von Mises (b) and equivalent plastic strain (c) distributions

\section{ACKNOWLEDGEMENTS}

The support of Martin Socima from QUANTECH ATZ in the numerical simulations performed is gratefully acknowledged.

\section{REFERENCES}

Fig. 11. Temperature distribution and shrinkage (plane xy)

Agelet de Saracibar, C., Cervera, M., Chiumenti, M., 1999, On the formulation of coupled thermoplastic problems with phase-change, Int. J. Plasticity, 15, 1-34.

Agelet de Saracibar, C., Cervera, M., Chiumenti, M., 2001, On the constitutive modeling of coupled thermomechanical phase change problems, Int. J. Plasticity, 17, 1565-1622.

Agelet de Saracibar, C., 2003, Simulación Numérica de Problemas Termomecánicos, Monograph M75, CIMNE, Barcelona

Agelet de Saracibar, C., Chiumenti, M., Cervera, M., Valverde, Q., 2004, On the Orthogonal Subgrid Scale Pressure Stabilization of Small and Finite Deformation J2 Plasticity, Monograph CMFP 2, CIMNE, Barcelona. 
Agelet de Saracibar, C., Chiumenti, M., Valverde, Q., Cervera, M., 2006, On the Orthogonal Subgrid Scale Pressure Stabilization of Finite Deformation J2 Plasticity", Computer Methods in Applied Mechanics and Engineering, 195, 1224-1251.

Brezzi, F., Fortin, M., 1991, Mixed and Hybrid Finite Element Methods, Spinger, New York.

Cervera, M., Agelet de Saracibar, C., Chiumenti, M., 1999, Thermo-mechanical analysis of industrial solidification processes, Int. J. Num. Meths. Engng., 46, 1575-1591.

Cervera, M., Chiumenti, M., Valverde, Q., Agelet de Saracibar, C., 2003, Mixed Linear/linear Simplicial Elements for Incompressible Elasticity and Plasticity, Computer Methods in Applied Mechanics and Engineering, 192, 5249-5263.

Chiumenti, M., Agelet de Saracibar, C., Cervera, M., 1999, Constitutive modelling and numerical analysis of thermomechanical phase-change systems, Monograph M48, CIMNE, Barcelona.

Chiumenti, M., Valverde, Q., Agelet de Saracibar, C., Cervera, M., 2002, A stabilized formulation for elasticity using linear displacement and pressure interpolations, Computer Methods in Applied Mechanics and Engineering, 191, 5253-5264.

Chiumenti, M., Valverde, Q., Agelet de Saracibar, C., Cervera, M., 2004, A stabilized formulation for incompressible plasticity using linear triangles and tetrahedral", Int. Journal of Plasticity, 20, 1487-1504.

Christ, D., Cervera, M., Chiumenti, M., Agelet de Saracibar, C., 2003, A Mixed Finite Element Formulation for Incompressibility using Linear Displacement and Pressure Interpolations, Monograph M77, CIMNE, Barcelona.

Codina, R., 2000, Stabilization of incompressibility and convection through orthogonal sub-scales in finite element methods, Computer Methods in Applied Mechanics and Engineering, 190, 1579-1599.

Codina, R., 2002, Stabilized finite element approximation of transient incompressible flows using orthogonal subscales", Computer Methods in Applied Mechanics and Engineering, 191, 4295-4321.

Hallam, C.P., Griffiths, W.D., Butler, N.D., 2000, Modelling of the interfacial heat transfer between an Al-Si alloy casting and a coated die stel, Proc. IX Int. Conf. on Modelling of Casting, Welding and Advanced Solidification processes, U.S.A., 2000.

Ransing, R.S., Lewis, R.W., 1998, Thermo-Elasto-Visco-Plastic Analysis for Determining Air Gap and Interfacial Heat Transfer Coupled with the Lewis-Ransing Correlation for Optimal Feeding Design", Proceedings of VIII International Conference on Modelling of Casting, Welding and Advanced Solidification processes, San Diego.
Valverde, Q., Agelet de Saracibar, C., Cervera, M., Chiumenti, M., 2002, Elementos Estabilizados de Bajo Orden en Mecánica de Sólidos, Monograph M69, CIMNE, Barcelona.

VULCAN, Software for simulation of casting processes, QUANTECH ATZ, www.quantech.es/vulcan

\section{STAN BADAŃ NAD SPRZĘŻONYM CIEPLNO-MECHANICZNYM MODELEM PROCESÓW ODLEWANIA METALI}

\section{Streszczenie}

W artykule opisano stan badań nad cieplno-mechanicznym modelem procesów odlewania metali. Termodynamicznie spójny konstytutywny model materiału został opracowany w oparciu o funkcję termo-lepkoplastycznej energii swobodnej. Ciagłe przejście od cieczy do ciała stałego modelowano za pomoca termo-lepkoplastycznego modelu typu J2. W konsekwencji, stosownie do zmian ułamka objętości fazy stałej termosprężysto-lepkoplastyczny model, opracowany dla ciał w stanie stałym, jest przekształcany w termo-lepkoplastyczny model odpowiedni dla cieczy. Do programu wprowadzono termolepkoplastyczny model styku, uwzględniający izolacyjny wpływ szczeliny powietrza powstającej w wyniku skurczu objętościowego krzepnącego metalu. W rozwiązaniu sprzężonego problemu zastosowano metodę kroków cząstkowych, wynikającą z operatorowego rozdziału różniczkowego równania cząstkowego. W rozwiązaniu metodą elementów skończonych zastosowano wieloskalową metodę stabilizacji w elementach niskiego rzędu. Jest to efektywna metoda pozwalająca ominąc kryterium Babuski-Brezzi'ego i uniknąć lokingu objętościowego i niestabilności ciśnienia powstających $\mathrm{w}$ quasi-nieściśliwych problemach. Symulacje przemysłowych procesów odlewania wykazały dobrą dokładność opracowanego modelu.

Received: March 2, 2006 Received in a revised form: May 3, 2006 Accepted: May 10, 2006 